\title{
Voice change in the stimulus suffix effect: Are the effects structural or strategic?
}

\author{
SETH N. GREENBERG \\ Union College, Schenectady, New York \\ and \\ RANDALL W. ENGLE \\ University of South Carolina, Columbia, South Carolina
}

\begin{abstract}
The literature on the stimulus suffix effect shows that if the suffix is presented in a voice different from that in which the list items are presented, there is less of a decrement in list recall than if the suffix is presented in the same voice. This experiment attempted to answer the question of whether this variable diminishes the suffix effect because of attentional factors or because of structural properties of echoic memory. Subjects received lists of digits in a male voice and either a tone, same-voice suffix, or different-voice suffix. Subjects received either the same suffix for all lists or two different suffixes. Those subjects given two suffixes and those given two tones were either forced to discriminate between them or had no discrimination requirement. The results demonstrated that voice change has both attentional and structural consequences on the suffix effect, with the attentional factors being confined to the preterminal positions and the structural factors being confined to the last position or two.
\end{abstract}

The principle technique for studying echoic or auditory sensory memory is the suffix procedure, in which a redundant nonrecalled speech sound is appended to the end of a short list of spoken items that are to be recalled in a generally serial fashion. The typical finding is a decrement in recall for the last few items in the suffix lists, compared with recall for lists with no suffix. Although this technique is not without its skeptics (cf. Kahneman, 1973), it has been by far the most common instrument used to study echoic memory since its introduction by Crowder and Morton (1969). Crowder and his colleagues have attempted to determine the characteristics of echoic memory by varying the nature of the list items and the suffix and temporal relationship between them.

In 1972, Crowder described the following characteristics of echoic memory as determined by using the suffix procedure: (1) echoic memory appears to be speech specific, since nonspeech sounds cause no decre-

This work was supported by a Union College Faculty Research Fund grant to the first author and by Grants HD-11114 and HD-15425 from NICHHD to the second author. We would like to especially thank David Balota for collecting data and for advice on the project, Julie Wildman for collecting data, Adrienne Issler and Mary Ann Popiel for scoring the data, and Henry Roedigger for his insightful criticism. The tone-discrimination condition was recommended by two anonymous reviewers. Requests for reprints should be sent to Seth Greenberg, Psychology, Union College, Schenectady, New York 12308, or to Randall Engle, Psychology, University of South Carolina, Columbia, South Carolina 29208. ment in recall, (2) echoic memory seems to retain only information about physical features of the speech input, (3) semantic content does not seem to be important to echoic memory, since the suffix can be any speech sound, such as backward speech, words, digits, and even the word "recall," and (4) the store appears to retain mostly vowel information or to retain vowel information longer (Darwin \& Baddeley, 1974).

There is now controversy surrounding each of these characteristics to such an extent that some researchers seem to question the need for echoic memory as a separate construct (Kallman \& Massaro, 1983; Nairne \& Walters, 1983). Much of this controversy stems from: (1) the word of Spoehr and Corin (1978), in which a silent but lip-read suffix led to a reduction in recall, (2) the work of Ayres, Jonides, Reitman, Egan, and Howard (1979), in which the observation of a suffix effect when the nasally spoken sound "wa" was used as a suffix depended on how the subject was set to interpret the sound, and (3) the work of Salter and Colley (1977), in which the semantic relatedness of the suffix and list items had an effect on the magnitude of the suffix effect.

It is our contention that much of this controversy arises from two erroneous lines of thought. One is that, because two conditions give a similar pattern of memory performance, they are necessarily a result of the same underlying mechanism. This, of course, is a gross non sequitur. Nevertheless, to our knowledge, none of the disconfirming findings listed above has been followed by research demonstrating 
that the finding is affected by the same variables that have been shown to affect the traditional suffix condition. The other is that it appears to be erroneous to think of the suffix effect as resulting from a unitary mechanism. It is our belief that the suffix effect is really a combination of at least two mechanisms and that either one of these can lead to a reduction in performance for the suffix condition. Following ideas presented by Morton (1976) and by Morton, Marcus, and Ottley (1981), Balota and Engle (1981) demonstrated that, whereas the suffix effect may extend over the last 5.6 serial positions, the preterminal effect is influenced by practice and by presentation rate and the effect for the terminal serial position is unaffected by these variables. We concluded there that "the" suffix effect is a result of both attentional and structural factors, with the preterminal effect being primarily attentional or strategic and the terminal effect being primarily structural, that is, echoic, in nature.

It was our purpose here to test whether the effect of one of the variables shown to influence the suffix effect-physical similarity of the suffix and list itemsis mediated by attentional factors, structural factors, or both. Morton, Crowder, and Prussin (1971) showed that changes in the pitch of the voice (from male to female or vice versa) from the list to the suffix caused a reduced suffix effect. Crowder (1978) interpreted this effect of voice shifts between list and suffix as resulting from reduced erasure of the echoic trace because of reduced physical similarity, much as visual masking is affected by similarity between a target and mask. However, Elmes (1974) and Watkins and Watkins (1980) both interpreted the results of their studies as reflecting attentional rather than structural factors. As Watkins and Watkins stated, "The interpretation we favor is that a voice change for the suffix enables the subject to give it less attention. If the subject is able to capitalize on a difference in voice quality to help him to ignore the suffix, then presumably the list items will suffer less interference" (p. 30).

The experiment reported here was an attempt to investigate whether presenting the suffix in a voice different from that in which the list items are presented brings about the reduced suffix effect through attentional or structural mechanisms, or both. Our hypothesis was that varying the degree to which the suffix demands attention should interact with the effect of changing the voice in which the suffix is presented if the attentional view is correct. In other words, if a condition requires that more attention be paid to the suffix, then changing the voice in which the suffix is presented should lead to less of a reduction in the suffix effect. By Watkins and Watkins' reasoning, the subject would still have to attend to the suffix in spite of the voice change. If changing the voice in which the suffix is presented has structural consequences, then manipulating the attentional demands of the task should lead to little or no change in the magnitude of the suffix effect. A third alternative is that changing the voice in which the suffix is presented affects both the structural and attentional components. In that case, we might expect to see that varying the attention demands of the suffix would differentially affect recall from the preterminal and terminal serial positions, with preterminal recall being affected and recall from the last position or two not being affected.

\section{METHOD}

\section{Subjects}

One hundred and thirteen students from the University of South Carolina and 16 students from Union College served as the subjects as a means of receiving course credit or as volunteers. They were tested in groups of 6-10.

\section{Materials and Design}

Each subject received the same order of 96 randomly generated eight-digit lists. Only the digits $1-10$ were used, and no digit appeared more than once in a list. Digit lists were spoken at a rate of 3 digits/sec in a male voice. Care was taken to record all digits in a monotone and to have no inflection at the end of the list. The suffix followed the last digit in the list in synchrony with other list items. There were five different between-subjects conditions, defined in terms of the nature of the item or suffix following the last item to be remembered. In the tone (control), or no-suffix, condition, the suffix was a $700-\mathrm{Hz}$ tone lasting $300 \mathrm{msec}$; in the single-suffix condition, the word "Go" always followed the last list item. There were two variable-suffix conditions, one in which the suffix was the word "Go" and one in which it was the word "Call." In the no-discrimination condition, both the words "Call" and "Go" required that the subject try to recall the eight-digit list. In other words, the subject did not need to make a discrimination between the two suffixes prior to recall, and the suffixes could be attended to superficially. In what is referred to here as the discrimination condition, the subject was only to recall half the lists-those cued by the word "Go." When a list was followed by the word "Call," the subject was to write the letters A-H on the answer sheet in lieu of the list items. Thus, this condition required the subject to make a discrimination and therefore demanded that more attention be paid to the suffix than did the other conditions. A comparable tone-discrimination condition required that the subject recall the digit list following a $700-\mathrm{Hz}$ tone and report $\mathrm{A}-\mathrm{H}$ following a $1500-\mathrm{Hz}$ tone. Thus, the five conditions, each presented to a different group of subjects, were single suffix, variable suffix with discrimination task, variable suffix with no discrimination task, tone (control) with discrimination task, and tone (control) with no discrimination task.

The lists assigned to the suffix "Go" in the suffix/no-discrimination condition were the same lists assigned to the suffix "Go" in the suffix-discrimination condition and to the $700-\mathrm{Hz}$ tone in the tone-discrimination condition. The lists were likewise the same for the "Call" suffixes and the $1500-\mathrm{Hz}$ tone. The order of presentation of "Go" $(700-\mathrm{Hz})$ and "Call" $(1500-\mathrm{Hz})$ lists was randomized over 16-list blocks, with the restriction that each suffix word (tone frequency) be used equally of ten within the block. The subjects were assigned randomly to the conditions.

In each of the three voice conditions (i.e., those involving verbal suffixes), half of the suffixes were spoken in the same male voice that had spoken the digits (the "same" condition). The other half of the suffixes were spoken in a female voice (the "different" condition). The order of presentation of lists ending with same and different voice suffixes was randomized over blocks of 16 lists, with the restriction that each suffix 
voice be employed eight times within a block. An additional constraint was imposed on the variable-suffix conditions. Here, voice (same or different) was factorially combined with suffix words ("Go" or "Call") to produce four different suffix combinations. Each combination appeared randomly, but equally often, in a 16-list block. Furthermore, the particular suffix combination assigned to a list in the discrimination condition was also assigned to that same list in the no-discrimination condition.

\section{Procedure}

The subjects were told what to expect at the beginning of the session. They were given a response sheet containing 96 rows of eight dashed lines and were told to write their responses in the appropriate spaces. The subjects were instructed to recall digit lists in a left-to-right order, with no regressions. The subjects in the discrimination condition were told to do the same with the letters A-H when the list ended with the word "Call" ( $1500-\mathrm{Hz}$ tone). A list took $3 \mathrm{sec}$ to present (including the suffix or tone), and the subjects were given $15 \mathrm{sec}$ between lists for recall. List presentation always began with the word "Ready" and a $1-\mathrm{sec}$ pause so that subjects could prepare to hear the upcoming list.

\section{RESULTS}

Analysis was restricted to the data collected from a particular set of 40 lists-by design, the same 40 lists from each of five suffix conditions. The lists contributing to the analysis were those presented among the final 80 that were assigned the suffix "Go" $(700 \mathrm{~Hz})$ when they appeared in the variable-suffix conditions (tone-discrimination condition). Again by design, 20 of the lists ended with the suffix "Go" spoken in the same voice in which the digits had been spoken and 20 ended with "Go" spoken in the different voice. Lists in the tone condition were yoked to the same- and differentvoice lists in the suffix conditions, and were so designated in the analysis. The recall performance was assessed using an all-or-none scoring procedure typically used in suffix effect studies. The subjects were given credit for a correct response when, and only when, the correct digit was recalled in the correct serial position.

The data were first analyzed in an analysis of variance (ANOVA), with the factors being suffix/tone $(\mathrm{S} / \mathrm{T})$ condition (5), voice (2), and serial position (8). This analysis resulted in all effects being significant $(\mathrm{p}<.001)$, with main effects of $S / T$ condition $[F(4,124)=6.63$, $\mathrm{MSe}=144.2]$, voice $[\mathrm{F}(1,124)=64.76, \mathrm{MSe}=6.7]$, and serial position $[\mathrm{F}(7,868)=193.5, \mathrm{MSe}=10.1]$ and with interactions of $S / T$ condition and voice $[F(4,124)=$ $6.8, \mathrm{MSe}=6.7]$, condition and serial position $[\mathrm{F}(28,868)$ $=6.08, \mathrm{MSe}=9.99]$, voice and serial position $[\mathrm{F}(7,868)$ $=27.97, \mathrm{MSe}=2.3]$, and condition, voice, and serial position $[F(28,868)=4.37$, MSe $=2.3]$. Since this analysis was too global to allow us to look at the effects hypothesized at the beginning of the experiment, finer grained analyses were performed. Newman-Keuls comparisons showed that the single-suffix condition did not differ from the variable-suffix/no-discrimination condition at any single serial position (all $\mathrm{p}$ values greater than .25) for either same or different voice conditions.
This meant that recall was unaffected by whether the lists were followed by the same suffix or two different ones. Thus, these conditions were combined and are shown, along with the discrimination-condition data, in Figure 1. The tone (control) data are plotted in both panels for comparison.

The question that motivated this study suggested that we might look for differences in recall for preterminal and terminal serial positions, and, indeed, examination of Figure 1 suggests that the interaction of the condition and voice variables was reflected only in recall performance of Positions 3-6. Therefore, we restructured the data by obtaining a mean for Positions 3-6 and another mean for Positions 7 and 8 for each condition and each subject. In addition, the percent relative suffix effect for each of the voice conditions was obtained by subtracting the mean recall in the suffix condition from the mean recall in the appropriate tone condition, dividing by the mean recall in that tone condition, and multiplying by 100 . Inspection of these data in Table 1 and the data in Figure 1 demonstrates several points relevant to the question of whether changes in the suffix effect brought about by changing the voice in which the suffix is presented are mediated by attentional or structural factors. In the no-discrimination condition, that condition most closely approximating other studies that have examined the effects of voice changes on the suffix effect, both same- and different-voice conditions give rise to a suffix effect over terminal and preterminal serial positions. However, the different-voice suffix clearly leads to less of a decrement, over both terminal and preterminal positions, than does the same-voice suffix. There is a decrease in the magnitude of the relative suffix effect for both preterminal and terminal positions with the different-voice suffix, but the decrease is obviously greater over the terminal positions.

Looking now at the recall data for when the subjects had to perform the discrimination task on the suffixes and tones, we can see that, compared with the nodiscrimination condition, there is a general decrement in performance for all three conditions. Comparing the relative suffix effects for the two discrimination condi-

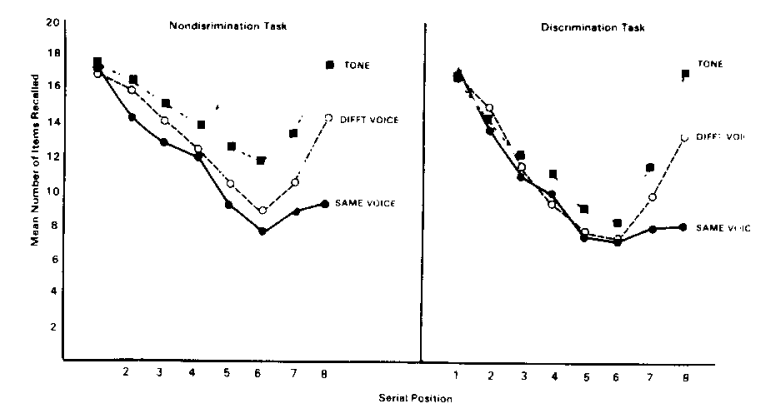

Figure 1. Mean number of digits recalled as a function of the voice in which the suffix was presented, whether or not the list was followed by a suffix and whether or not the subject had to discriminate between the different suffixes. 
Table 1

Mean Recall and Relative Suffix Effect (RSE, in Percent) From Preterminal (3-6) and Terminal (7 and 8) Serial Positions for the Discrimination and No-Discrimination Conditions

\begin{tabular}{|c|c|c|c|c|c|c|c|c|}
\hline \multirow[b]{3}{*}{ Condition } & \multicolumn{4}{|c|}{ No-Discrimination Task } & \multicolumn{4}{|c|}{ Discrimination Task } \\
\hline & \multicolumn{2}{|c|}{ Preterminal Positions } & \multicolumn{2}{|c|}{ Terminal Positions } & \multicolumn{2}{|c|}{ Preterminal Positions } & \multicolumn{2}{|c|}{ Terminal Positions } \\
\hline & Mean Recall & RSE & Mean Recall & RSE & Mean Recall & RSE & Mean Recall & RSE \\
\hline Tone & 13.28 & & 15.22 & & 10.12 & & 14.46 & \\
\hline Different Voice & 11.43 & $13.9 \%$ & 12.40 & $18.5 \%$ & 8.75 & $13.5 \%$ & 11.40 & $21.2 \%$ \\
\hline Same Voice & 10.25 & $22.8 \%$ & 9.10 & $40.2 \%$ & 8.75 & $13.5 \%$ & 8.00 & $44.7 \%$ \\
\hline
\end{tabular}

Note-The percent relative suffix effect was calculated by the following formula: (mean tone-condition recall - mean suffix-condition recall)/mean tone-condition recall.

tions in Table 1, we see an interesting pattern of results. First of all, we see that requiring subjects to attend to the suffix had comparatively little impact on the suffix effect for the terminal positions. We also see that, with both the discrimination and no-discrimination tasks, the terminal suffix effect for the different voice was about half that for the same-voice suffix. The relative suffix effect for the preterminal positions gives a different, but somewhat misleading, pattern of results. It appears that the discrimination requirement leads to no change for the different-voice condition but leads to a large reduction in the magnitude of the preterminal suffix effect for the same-voice condition. This is misleading because, in actuality, the discrimination task led to a greater decrease in the mean recall performance in the tone and different-voice conditions than in the same-voice condition. Whereas there is comparatively little change in the same-voice condition, the change in the baseline condition, that is, the tone condition, leads to a smaller relative suffix effect. Since the discrimination requirement led to about the same decrement for the differentvoice condition as for the tone condition over the preterminal positions, the magnitude of the differentvoice preterminal suffix is about the same as that of the no-discrimination condition. Table 2 shows the difference in mean recall between the discrimination and nodiscrimination conditions over the preterminal and terminal positions for the tone, different-voice, and samevoice conditions. There we can see that the effect of the discrimination task was minimal on recall from the terminal positions and only slightly larger for the preterminal positions in the same-voice condition. However,

Table 2

Difference in the Mean Recall Scores Between the Discrimination and No-Discrimination Tasks for the Preterminal and Terminal Positions for the Tone, Different-Voice, and

Same-Voice Conditions

\begin{tabular}{lcc} 
Condition & $\begin{array}{c}\text { Preterminal } \\
\text { Positions }\end{array}$ & $\begin{array}{c}\text { Terminal } \\
\text { Positions }\end{array}$ \\
\hline Tone & 3.16 & .76 \\
Different Voice & 2.68 & 1.00 \\
Same Voice & 1.50 & 1.10 \\
\hline
\end{tabular}

the impact of the discrimination task was sizable on the recall from the preterminal positions in the baseline tone condition and the different-voice suffix condition.

Thus, we can draw several conclusions about the impact of requiring the subject to attend to the suffix. First, there is little or no effect on the recall from terminal positions for either of the two voice conditions or the tone condition; therefore, there is little or no change in the magnitude of the terminal-position suffix effect for either of the two voice conditions. In addition, for both discrimination conditions, the terminal suffix effect in the different-voice condition was about half that for the same-voice condition. Second, although there was a sizable effect of discrimination on the recall from the preterminal positions in the tone and the different-voice conditions, there was less impact on the preterminal recall in the same-voice condition. The result was that preterminal performance in both the tone and the different-voice conditions was more like that in the same-voice condition.

We are led to conclude that the attentional demands resulting from the discrimination task interact with the physical similarity of the suffix to the list items only over the preterminal positions. The suffix effect for the terminal positions in each of the two voice conditions appears to be unaffected by secondary task demands like those in the discrimination task. These conclusions were supported by ANOVAs, with the serial-position factor represented by the means of Positions 3-6 as one level and the means of Positions 7 and 8 as the other level. One analysis, which excluded the tone conditions, resulted in the significant conditions $\mathrm{x}$ voice $\mathrm{x}$ serial position interaction shown in Figure 1 and Table 1 $[\mathrm{F}(1,83)=4.66, \mathrm{MSe}=1.65, \mathrm{p}<.04]$, and a second analysis of tone condition, with and without discrimination, yielded a significant condition $\mathrm{x}$ serial position interaction $[\mathrm{F}(1,42)=11.10, \mathrm{MSe}=29.67$, $\mathrm{p}<.005]$. This is clearly shown in Figure 1 and Table 2.

\section{DISCUSSION}

The purpose of this experiment was to investigate the cause of the decrease in the magnitude of the stimulus suffix effect when the suffix is presented in a voice different from that in which the list items are pre- 
sented. We wanted to ascertain whether the decrease was a result of structural factors, as Crowder (1978) had argued, or of attentional factors, as Watkins and Watkins (1980) had argued. The results of the study appear to be quite straightforward in demonstrating that both factors are important in mediating this phenomenon but that each is important over a different part of the serial-position function. Forcing attention to a different-voice suffix led to a suffix effect over the preterminal positions just as large as that for a samevoice suffix. This supports Balota and Engle's (1981) assertion that the suffix effect for the penultimate positions represents attentional and strategic factors that are probably independent of auditory sensory traces.

The fact that the difference between the same- and different-voice conditions for the terminal positions was not at all diminished when attention was forced to the suffix makes several points about echoic memory and the stimulus suffix procedure. This finding lends support to the notion that "the" suffix effect is really two different effects and that only the effects of the suffix on the terminal positions should be used to make inferences about structural aspects of echoic memory. Given that assumption, this study suggests that voice change does in fact alter the structural impact of the suffix on the echoic traces for the last item or two in a list. This, of course, supports Crowder's (1972, 1978) contention that echoic traces are impaired to the extent that new incoming information is speech that is similar along certain physical dimensions to the speech repre. sented by those traces.

What is the nature of the preterminal suffix effects, and, specifically, how does an attentional mechanism affect the decrement in performance? This study was not designed to answer those questions, and at this time we can only speculate. Attention to the suffix could cause preterminal decrements in performance in at least two, not mutually exclusive, ways. One way would be that in which attending to the suffix caused the suffix to be encoded such that its trace would cause proactive interference at the time of recall. Let us assume that all stimulus inputs coming over a nominally attended channel go through several levels of analysis and that the "deeper" or more elaborate the analysis, the stronger the resulting memory trace for that input. (Of course, this is the backbone of an approach taken by Craik \& Lockhart, 1972.) Any factor that caused the suffix to be more completely analyzed would result in a trace that caused some degree of proactive interference. It would be possible, with this mechanism, for the subject to so attend to the suffix that a different-voice suffix would lead to a smaller suffix effect over the terminal positions because of reduced structural masking but would cause no reduction over the preterminal positions because of a strong trace resulting from the suffix. That may be the reason that Watkins and Watkins (1980) found that a different-voice suffix led to a smaller suffix effect for only the last position but led to no reduction over the preterminal positions, whereas Morton et al. (1971) found a reduced suffix effect for both preterminal and terminal positions. Watkins and Watkins used words as stimuli and a different set for each list. This possibly could have forced the subject to analyze the suffix more fully before a decision could be made that it was, indeed, a suffix and therefore required no further analysis. Morton et al. (1971) used digits, and the degree of analysis necessary to make such a decision would be much less than if the stimuli were words.

The other manner in which attending to the suffix could cause preterminal decrements in recall would be that, very simply, it would reduce the amount of attention left over for the list items. Although this notion might seem trivial, it does seem to receive some support in the present data. It is unlikely that encoding the tone would lead to a trace that would cause proactive interference with the list items at the time of recall, and yet the requirement to discriminate between the two tone suffixes caused the greatest decrement for any condition in the discrimination condition. The degree of difficulty of the tone discrimination is almost surely different from the difficulty of the verbal suffix discrimination, but that is irrelevant. The fact is that being forced to attend to the tones caused almost no decrement in the recall of the terminal items but led to the greatest decline in the recall of the preterminal items. This seems to favor the second interpretation of attentionally caused deficits over preterminal positions.

\section{REFERENCES}

Ayres, T. J., Jonides, J., Reitman, J. S., Egan, J. C., \& Howard, D. A. Differing suffix effects for the same physical suffix. Journal of Experimental Psychology: Human Learning and Memory, 1979, 5, 315-321.

Balota, D. A., \& Engle, R. W. Structural and strategic factors in the stimulus suffix effect. Journal of Verbal Learning and Verbal Behavior, 1981, 20, 346-357.

Craik, F. I. M., \& Lockhart, R. S. Levels of processing: A framework for memory research. Journal of Verbal Learning and Verbal Behavior, 1972, 11, 671-684.

Crowder, R. G. Visual and auditory memory. In J. F. Kavanaugh \& I. G. Mattingly (Eds.), Language by ear and by eye: The relationships between speech and reading. Cambridge, Mass: MIT Press, 1972.

Chowder, R. G. Mechanisms of auditory backward masking in the stimulus suffix effect. Psychological Review, 1978, 85, 502-524.

Crowder, R. G., \& Morton, J. Precategorical acoustic storage (PAS). Perception \& Psychophysics, 1969, 5, 365-373.

Darwin, C. J., \& Baddeley, A. D. Acoustic memory and the perception of speech. Cognitive Psychology, 1974, 6, 41-60.

Elmes, D. G. Isolation of items and the stimulus suffix effect. Memory \& Cognition, 1974, 2, 345-348.

Kahneman, D. Attention and effort. Englewood Cliffs, N.J: Prentice-Hall, 1973. 
Kallman, H. J., \& Massaro, D. W. Backward masking, the suffix effect and preperceptual storage. Journal of Experimental Psychology: Learning, Memory and Cognition. 1983, 9, 312-327.

Morton, J. Two mechanisms in the stimulus suffix effect. Memory \& Cognition, 1976, 4, 144-149.

Morton, J., Chowder, R. G., \& Prussin, H. A. Experiments with the stimulus suffix effect. Journal of Experimental Psychology, 1971, 91, 169-190.

Morton, J., Marcus, S. M., \& Ottley, P. The acoustic correlates of "speechlike": A use of the suffix effect. Journal of Experimental Psychology: General, 1981, 110, 568-593.

Nairne, J. S., \& Walters, V. L. Silent mouthing produces modality-and suffixlike effects. Journal of Verbal Learning and Verbal Behavior, 1983, 22, 475-483.
Salter, D., \& Colley, J. G. The stimulus suffix: A paradoxic effect. Memory \& Cognition, 1977, 5, 257-262.

Spoenr, K. T., \& Corin, W. J. The stimulus suffix effect as a memory coding phenomenon. Memory \& Cognition, 1978, 6, 583-589.

Watkins, O. C., \& Watkins, M. J. Echoic memory and voice quality: Recency recall is not enhanced by varying presentation voice. Memory \& Cognition, 1980, 8, 26-30.

(Manuscript received December 20, 1982; revision accepted for publication June 1,1983 .) 